\title{
Ivermectin as an endectocide may boost control of malaria vectors in India and contribute to elimination
}

\author{
Sundus Shafat Ahmad ${ }^{1}$, Manju Rahi ${ }^{2,4}$, Poonam Saroha ${ }^{1,4}$ and Amit Sharma ${ }^{1,3,4^{*}}$ (i)
}

\begin{abstract}
Malaria constitutes one of the largest public health burdens faced by humanity. Malaria control has to be an efficient balance between diagnosis, treatment and vector control strategies. The World Health Organization currently recommends indoor residual spraying and impregnated bed nets as two malaria vector control methods that have shown robust and persistent results against endophilic and anthropophilic mosquito species. The Indian government launched the National Framework for Malaria Elimination in 2016 with the aim to achieve the elimination of malaria in a phased and strategic manner and to sustain a nation-wide malaria-free status by 2030. India is currently in a crucial phase of malaria elimination and novel vector control strategies maybe helpful in dealing with various challenges, such as vector behavioural adaptations and increasing insecticide resistance among the Anopheles populations of India. Ivermectin can be one such new tool as it is the first endectocide to be approved in both animals and humans. Trials of ivermectin have been conducted in endemic areas of Africa with promising results. In this review, we assess available data on ivermectin as an endectocide and propose that this endectocide should be explored as a vector control tool for malaria in India.
\end{abstract}

Keywords: Endectocide, Ivermectin, Malaria elimination, Vector control

\section{Background}

Malaria is a significant public health issue in India, with a complex heterogeneity due to the presence of six major anopheline vector species across different eco-geographical regions of the country [1]. In recent years, these vectors have shown a change in distribution and behaviour. The estimated number of malaria cases worldwide in 2019, as reported by the World Health Organization (WHO) in the World Malaria Report 2020, was 229 million, with the South-East Asia region accounting for 3\% of all malaria cases worldwide [2]. Although the WHO reported that India had achieved the highest reduction

*Correspondence: directornimr@gmail.com

${ }^{1}$ Indian Council of Medical Research (ICMR)-National Institute of Malaria Research, New Delhi, India

Full list of author information is available at the end of the article in malaria cases of all countries tabulated (i.e. from 20 million cases in 2000 to 5.6 million in 2019), it still accounted for $\sim 86 \%$ of all malaria associated deaths in South Asia [2]. These losses can be avoided as malaria is considered to be a preventable and curable disease. Vector control has always been a vital component of malaria control strategies. Long-lasting impregnated insecticide bed nets (LLINs) and indoor residual insecticide sprays (IRS) are the backbone of vector control strategies and have contributed to reducing the burden of malaria [3]. Between 2000 and 2015, IRS and LLINs have collectively accounted for a decline of $\sim 78 \%$ in malaria cases in endemic regions of Africa [4].

The increasing resistance of Anopheles spp. to currently used insecticides is an impending threat to malaria management programmes $[5,6]$. In addition, changes in vector behaviour to earlier biting and outdoor biting original author(s) and the source, provide a link to the Creative Commons licence, and indicate if changes were made. The images or other third party material in this article are included in the article's Creative Commons licence, unless indicated otherwise in a credit line to the material. If material is not included in the article's Creative Commons licence and your intended use is not permitted by statutory regulation or exceeds the permitted use, you will need to obtain permission directly from the copyright holder. To view a copy of this licence, visit http://creativecommons.org/licenses/by/4.0/. The Creative Commons Public Domain Dedication waiver (http://creativeco mmons.org/publicdomain/zero/1.0/) applies to the data made available in this article, unless otherwise stated in a credit line to the data. 
patterns have been documented in India and elsewhere $[5,6]$. Such changes in vector behaviour impact both LLINs and IRS [6]. Many vector control tools have been tested in research settings such as insecticide-impregnated hammocks, insecticide-treated clothing, footwear, strips, wall linings, wall paints, spatial/airborne repellents, topical repellents, mosquito traps, attractive toxic sugar baits and endectocides [7, 8]. Endectocides are drugs with both endoparasitocidal and ectoparasitocidal activity, and they are widely used in veterinary medicine. One such anti-parasitic agent is ivermectin which is also approved for human use [3].

\section{Retrieval of information}

Available data on ivermectin as an endectocide was retrieved from published medical and veterinary entomology documents. We performed an online search of the PubMed, Cochrane Library, Google and Google Scholar bibliographic databases for scientific papers published from 2010 until the present, using a combination of the following search terms: "vector control", "vector control methods", "malaria", "endectocide", "ivermectin" and "Anopheles". The search identified 15 completed trials that satisfied the search criteria for this review: seven human trials and eight cattle trials (see Tables 1,2). Data from ongoing trials were retrieved from the Malaria Eradication Scientific Alliance. Treatment guidelines

Table 1 Major ivermectin studies in humans

\begin{tabular}{lll}
\hline $\begin{array}{l}\text { Trial name/first } \\
\text { author of study(year) } \\
\text { [reference] }\end{array}$ & Dosage of ivermectin & Results: mortality of mosquito \\
\hline
\end{tabular}

$\begin{array}{ll}\text { ACTIVE [24] } & 200 \mu \mathrm{g} / \mathrm{kg} \text { as a single dose or } 200 \mu \mathrm{g} / \mathrm{kg} \text { for } 2 \text { days as two } \\ 2013 & \text { doses or placebo; all administered with artemether-lume- } \\ \text { Burkina Faso } & \text { fantrine }\end{array}$

Burkina Faso

\begin{tabular}{|c|c|}
\hline $\begin{array}{l}\text { RIMDAMAL [15] } \\
2015 \\
\text { Burkina Faso }\end{array}$ & $\begin{array}{l}\text { First dose of } 150-200 \mu \mathrm{gg} / \mathrm{kg} \text { single dose with } 400 \mathrm{mg} \text { alben } \\
\text { dazole plus five further similar ivermectin doses at 3-week } \\
\text { intervals }\end{array}$ \\
\hline $\begin{array}{l}\text { IVERMAL [25] } \\
2015 \\
\text { Kenya }\end{array}$ & $\begin{array}{l}300 \mu \mathrm{gg} / \mathrm{kg} \text { for } 3 \text { days or } 600 \mu \mathrm{gg} / \mathrm{kg} \text { for } 3 \text { days or placebo; all } \\
\text { administered with dihydroartemisinin-piperaquine }\end{array}$ \\
\hline $\begin{array}{l}\text { Derua [26] } \\
2015 \\
\text { Tanzania }\end{array}$ & $150-200 \mu \mathrm{g} / \mathrm{kg}$ \\
\hline $\begin{array}{l}\text { Sampaio [27] } \\
2016 \\
\text { Brazil }\end{array}$ & $200 \mu \mathrm{g} / \mathrm{kg}$ \\
\hline $\begin{array}{l}\text { Kobylinski [28] } \\
2017 \\
\text { Thailand }\end{array}$ & $200 \mu \mathrm{g} / \mathrm{kg}$ \\
\hline $\begin{array}{l}\text { Mekuriaw [14] } \\
2019 \\
\text { Ethiopia }\end{array}$ & Single oral dose of $12 \mathrm{mg}$ \\
\hline
\end{tabular}

An. gambiae

Mortality of mosquito in 3 days post blood meal (one dose of Ivermectin): $33 \%$

Mortality of mosquito in 3 days post blood meal (two doses of Ivermectin): $31 \%$

Controls: $6 \%$ mortality in 3 days (difference was significant)

Mortality of mosquito in 10 days post blood meal (one dose of Ivermectin): $59 \%$

Mortality of mosquito in 10 days post blood meal ( 2 doses of Ivermectin): $66 \%$

Controls: $21 \%$ mortality in 10 days (difference was significant) An. funestus

Mortality of mosquito in 3 days post blood meal (one dose of Ivermectin): $33 \%$

Mortality of mosquito in 3-days post blood meal (two doses of Ivermectin): $22 \%$

Controls: $3 \%$ mortality in 3 days (difference was significant)

Mortality of mosquito in 10 days post blood meal (one dose of Ivermectin): $40 \%$

Mortality of mosquito in 10 days post blood meal (two doses of Ivermectin): $51 \%$

Controls: $5 \%$ mortality in 10 days (difference was significant)

Frequently repeated mass administration of ivermectin during the malaria transmission season led to significant reduction in malarial episodes in children

3-Day ivermectin treatment at either of the doses reduced mosquito survival for at least 28-days-post feeding

Mortality of mosquito in 3 days post blood meal: $66.2 \%$ Mortality of mosquito in 9 days post blood meal: $95 \%$ Significance not reported

Ivermectin treatment reduces mosquito survivorship by $4 \mathrm{~h}$ to 14 days

Ivermectin was lethal to dominant GMS Anopheles malaria vectors and inhibited sporogony of $P$. vivax at safe human relevant concentrations

Significant higher mortality of mosquitos on days 1 and day 4 reported 
Table 2 Major ivermectin studies carried out in cattle

\begin{tabular}{|c|c|c|}
\hline $\begin{array}{l}\text { Study/first author } \\
\text { of study(year) } \\
\text { [reference] }\end{array}$ & Dosage of ivermectin & Mortality of mosquitos \\
\hline $\begin{array}{l}\text { Fritz [29] } \\
2009 \\
\text { Kenya }\end{array}$ & $600 \mu \mathrm{g} / \mathrm{kg}$ once subcutaneously & $\begin{array}{l}\text { Mortality of mosquitos in } 3 \text { days post blood meal, (feeding done one day after ivermectin } \\
\text { treatment): } 100 \% \\
\text { Controls: } 10 \% \text { (significance not reported) } \\
\text { Mortality of mosquitos in } 3 \text { days post blood meal (feeding done } 13 \text { days after ivermectin } \\
\text { treatment): } 62 \% \\
\text { Mortality of mosquitos in } 9 \text { days post blood meal (feeding done } 13 \text { days after ivermectin } \\
\text { treatment): } 88 \% \text {, } \\
\text { Controls: } 10-38 \% \text { (significance not reported) }\end{array}$ \\
\hline $\begin{array}{l}\text { Naz [17] } \\
2013 \\
\text { Pakistan }\end{array}$ & $200 \mu \mathrm{g} / \mathrm{kg}$ once subcutaneously & $\begin{array}{l}\text { An. culicifacies } \\
\text { Mortality of mosquito in } 3 \text { days post blood meal: } 65 \% \\
\text { Controls: } 9 \% \\
\text { Mortality of mosquito in } 9 \text { days post blood meal: } 80 \% \\
\text { Controls: } 17 \% \\
\text { An. stephensi } \\
\text { Mortality of mosquito in } 3 \text { days post blood meal: } 80 \% \\
\text { Controls: } 10 \% \\
\text { Mortality of mosquito in } 9 \text { days post blood meal: } 80 \% \\
\text { Controls: } 25 \%\end{array}$ \\
\hline $\begin{array}{l}\text { Pooda [30] } \\
2015 \\
\text { Burkina Faso }\end{array}$ & $200 \mu \mathrm{g} / \mathrm{kg}$ injected & $\begin{array}{l}\text { Reduction in mortality of mosquitos by } 75 \% \text { in the third week and by } 45 \% \text { in the fourth week } \\
\text { post ivermectin treatment }\end{array}$ \\
\hline $\begin{array}{l}\text { Poche [18] } \\
2015 \\
\text { Kenya }\end{array}$ & $100-200 \mu \mathrm{g} / \mathrm{kg}$ orally & $\begin{array}{l}\text { Mortality of mosquito in } 3 \text { days post blood meal: } 45-63 \% \\
\text { Mortality of mosquito in } 9 \text { days post blood meal: } 65-94 \%\end{array}$ \\
\hline $\begin{array}{l}\text { Lyimo [31] } \\
2017 \\
\text { Tanzania }\end{array}$ & $200 \mu \mathrm{g} / \mathrm{kg}$ once subcutaneously & Survival and fecundity of An. arabiensis were reduced by $52.5 \%$ and $64.6 \%$, respectively \\
\hline $\begin{array}{l}\text { Chaccour [19] } \\
2018 \\
\text { Tanzania }\end{array}$ & $\begin{array}{l}5 \text { subcutaneous implants } \\
\text { of } 23 \text { mg each, tested over } \\
40 \text { weeks }\end{array}$ & $\begin{array}{l}\text { Significant increased mortality of mosquitos in } 3 \text { days and } 10 \text { days after blood meal (signifi- } \\
\text { cant difference) }\end{array}$ \\
\hline $\begin{array}{l}\text { Cramer [16] } \\
2021 \\
\text { Vietnam }\end{array}$ & $200 \mu \mathrm{g} / \mathrm{kg}$ once subcutaneously & $\begin{array}{l}\text { Ivermectin treatment significantly reduced survivorship of An. dirus up to } 20 \text { days and An. } \\
\text { epiroticus up to } 8 \text { days }\end{array}$ \\
\hline $\begin{array}{l}\text { Makhanthisa [32] } \\
2021 \\
\text { South Africa }\end{array}$ & $200 \mu \mathrm{g} / \mathrm{kg}$ injected & $\begin{array}{l}\text { Significant increased mortality of mosquitos on day 7,13 and } 21 \text { post ivermectin treatment } \\
\text { and also lead to reduced egg production }\end{array}$ \\
\hline
\end{tabular}

and protocols were retrieved from official websites of the National Vector Borne Diseases Control Programme and WHO.

\section{Ivermectin use in malaria}

Ivermectin is a semi-synthetic avermectin derivative that was first licensed in 1981 as a veterinary drug and then approved in 1987 for use in humans due to its activity against the parasites of Onchocerca spp. [9]. It is currently authorized for the treatment of headlice, lymphatic filariasis, onchocerciasis, strongyloidiasis and scabies [10]. Over the past 30 years it has been found to be a remarkably potent insecticide and anthelmintic, especially against filarial worms [3]. The use of ivermectin for malaria vector control was first suggested in 1985, following publication of a study showing that this drug killed Anopheles stephensi in in vitro tests [9]. The basis of ivermectin-based malaria control is that it reduces the survival of mosquitoes that feed on human or cattle populations previously administered with ivermectin. Ivermectin has mosquitocidal activity, and its administration to humans and/or livestock reduces the lifespan of mosquitoes irrespective of biting patterns or host preference. Consequently, this drug has the potential to complement the existing toolbox of malaria vector control measures [11].

Recognizing the potential of ivermectin, the WHO Malaria Policy Advisory Committee (MPAC) in its technical consultation reviewed the available data on ivermectin in 2016. The MPAC put forward a policy recommendation that for ivermectin to be considered of public health relevance, at least $20 \%$ reduction in clinical malaria incidence has to be demonstrated at least 1 month post treatment with one round of mass 
administration of ivermectin [12]. However, the concept of using ivermectin as an endectocide against malaria vectors does pose an ethical conundrum. This drug is not given as a prophylaxis or as a malaria treatment, but as a vector control method targeting mosquitoes for the larger public good.

There have been several studies in Africa and Asia that have deployed ivermectin in humans as a vector control tool (Table 1). The most common dosage used in these trials was $150-200 \mu \mathrm{g} / \mathrm{kg}$ as single oral dose or up to $400 \mu \mathrm{g} / \mathrm{kg}$ in multiple doses [13]. Mass ivermectin treatment in human populations targets anthropophilic Anopheles vectors and endophagic Anopheles. Mekuriaw et al. [14] reported in 2019 that the mortality of mosquitoes fed on ivermectin-treated blood was significantly higher than that of the controls (13.8 vs $3.7 \%)$. These authors also reported that the fecundity of the ivermectin-treated mosquito populations was lower than that of the controls [14]. Most of the studies on the mosquitocidal activity of ivermectin have been conducted under controlled laboratory conditions. In contrast, a randomized controlled trial (RIMDAMAL) was conducted by Foy et al. [15] in 2015 in the field, and it demonstrated that children who had received ivermectin had reduced number of malaria episodes as compared to the control group and there was an overall reduction in malaria transmission. There was a reduced incidence of malaria episodes in the intervention arm (648 episodes in 327 children; average of 2 episodes per child) in comparison to the control arm (647 episodes in 263 children; average 2.5 episodes per child) [15].

There are a number of ongoing large-scale trials of ivermectin as an endectocide for malaria control, including RIMDAMAL II (Burkina Faso), MATAMAL(Guinea-Bissau), BOHEMIA (Tanzania- Mozambique), REACT (Burkina Faso and Côte d'Ivoire) and MASSIV (The Gambia) [13]. The effect of ivermectin when administered at a dose of $200 \mu \mathrm{g} / \mathrm{kg}$ to cattle targeting zoophagic mosquitoes has also been studied (Table 2). For cattle, there are a variety of administration modes/formulations, including subcutaneous, injectable and implantable (long-release solutions) [13]. A major trial by Cramer et al. [16], carried out by the University of Vietnam and University of Massachusetts, was based on zooprophylaxis-aided ivermectin-based vector elimination (ZAIVE) in 2021. The trial was carried out in Vietnam which has a significant problem with mosquitoes in forested areas. In this study, the mosquitoes were fed on cattle that had been injected subcutaneously with $0.2 \mathrm{mg} / \mathrm{kg}$ ivermectin (intervention arm) or not (control arm) and then these mosquitos were collected from both the intervention and control sites to analyse anopheline populations prior to and post dosing of cattle with ivermectin [16]. The mortality of the mosquitoes was checked for up to 30 days post feeding [16]. The results showed, for the first time in South-East Asia, that cattle treated with ivermectin at standard veterinary dosages led to reduced survival of two important malaria vectors, Anopheles epiroticus and Anopheles dirus [16]. It also determined that an adequate population of livestock dosed with ivermectin in peri-domestic situations would have a significant impact on anopheline numbers [16]. Reports by Naz et al. [17] in 2013 and Poche et al. [18] in 2015 also showed significant mortality among mosquitoes (80-95\%) fed on ivermectin-treated cattle.

There are advantages to administering ivermectin in cattle over human administration: (i) ivermectin administration in cattle targets a wide array of zoophagic Anopheles, thus reducing malaria transmission; (ii) it is easier to obtain institutional/regulatory agency approval for trials in animals compared to humans; (iii) long-lasting formulations and a wider diversity of formulations (injectable and implants) with longer drug half-life can be used in cattle. For example, Chaccour et al. [19] showed that an ivermectin formulation when implanted in cattle was successful in delivering medication for a duration of 6 months. This reduced malaria transmission and also showed a (iv) collateral benefit of increasing livestock weight gain and milk yield, which in turn helps the community [20].

India is predominately an agricultural society, with $70 \%$ of its population living in rural settings. In this setting, humans commonly cohabit with cattle and farm animals. Also, $70 \%$ of malaria in India is attributed to Anopheles culicifacies [1], a zoophilic species. Therefore, there is an increased probability of close contact between the general human population and animals and under such conditions, ivermectin administration to cattle populations will not only have a beneficial effect on suspectible human populations, but anthropophilic mosquitoes will also be targeted. In addition, an increased overall impact can be achieved as the resulting reduction in Anopheles density can enhance the action of commonly used vector control tools like LLINs and IRS, thereby augmenting their impact [11].

Figure 1 shows a global map of studies on the use of ivermectin as endectocide in humans and cattle. It should be noted that ivermectin is not a new drug to the Indian public health setup. Since 2018, the Indian National Programme to Eliminate Lymphatic Filariasis has incorporated ivermectin as the third drug along with albendazole and diethylcarbamazine as a preventive mass chemotherapy. The triple therapy is successfully deployed in 21 districts across the country (depicted in Fig. 2) [21].

Despite achieving a reduction in malaria burden in recent years, India reported 181,831 malaria cases in 


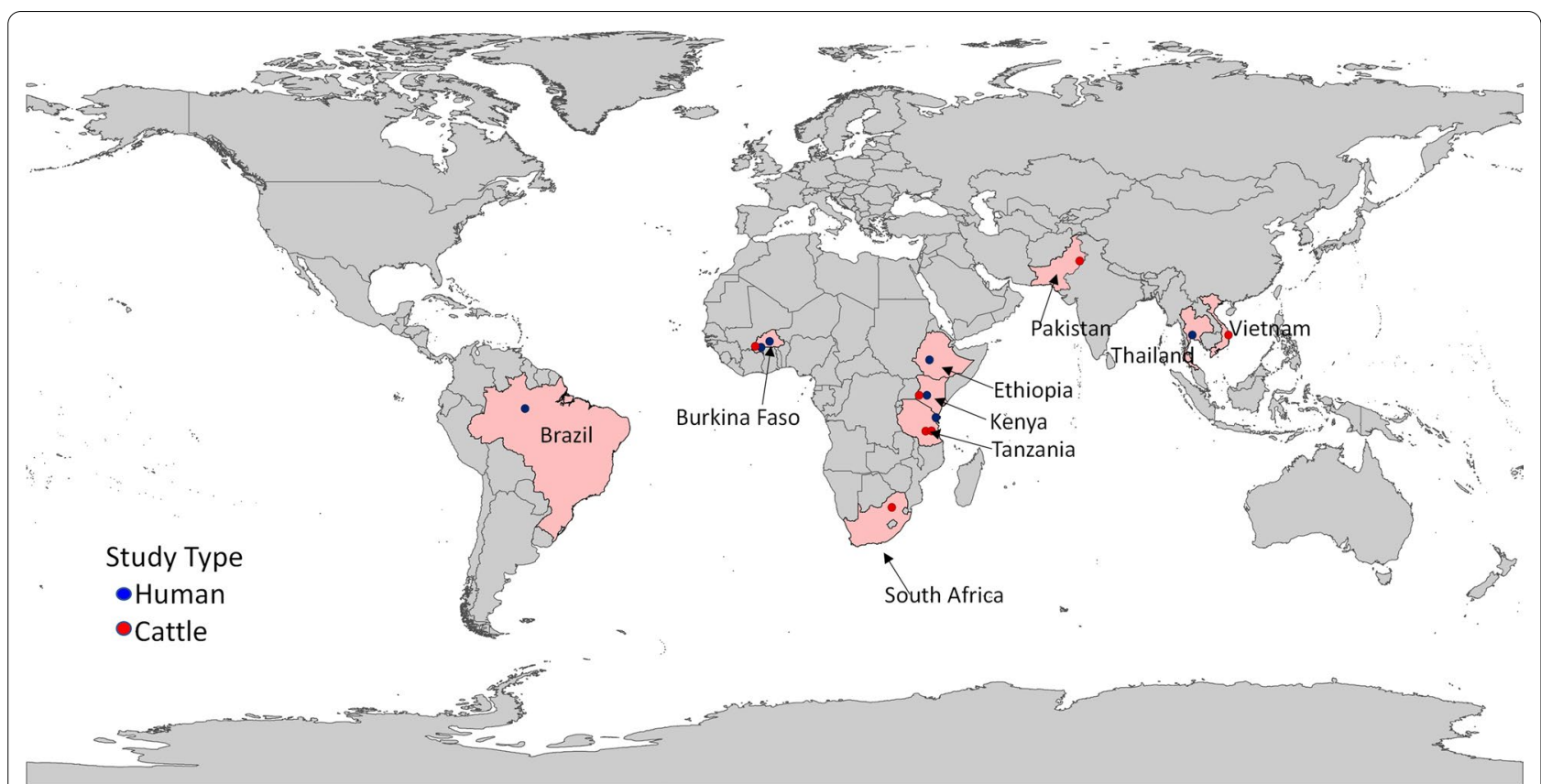

Fig. 1 Studies carried out worldwide using ivermectin for malaria vector control (2013-2021)

2020 [21]. As noted above, India is primarily a rural and agricultural state and houses $37 \%$ of the world's livestock [22]. In 2020, the state of Odisha accounted for $23 \%$ of all malaria cases in India, followed by the state of Chhattisgarh which shouldered 20\% [5]. Despite effective intervention tools, malaria burden continues to be high in certain districts of India, suggestive of residual malaria transmission wherein despite adequate coverage with effective vector control tools like ITNs and/or IRS malaria cases remain high [21].

\section{Steps to testing and evaluating ivermectin as endectocide in India}

Although ivermectin is an established drug in India, its usage targeting Indian malaria vectors needs to be researched. First, the susceptibility of Indian anopheline species to ivermectin is not known and needs to be established-especially for Anopheles culicifacies which is responsible for $>70 \%$ malaria transmission in India [1]. Second, the 50\% lethal dose (LD50) and 90\% lethal dose (LD90) for Indian malaria vectors needs to be determined followed by preclinical studies [23]. As a subsequent step, ivermectin could then be tested in cattle and human populations in malaria endemic areas in India for its impact on malaria vectors [12]. An existing mass drug administration (MDA) programme using ivermectin for lymphatic filariasis can be leveraged while planning ivermectin trials for malaria. The mosquitocidal effect of ivermectin on insecticide-resistant Anopheles spp. can also be evaluated as a potential advantage [12]. In accordance with WHO suggestions, study designs could include: (i) observational studies in locations where ivermectin MDA is already underway against lymphatic filariasis; (ii) cluster randomized controlled trials that estimate the benefits of ivermectin in addition to core vector control strategies and management of cases; and (iii) before and after studies of ivermectin MDA in control and intervention sites [12].

For human trials, it must be noted that subjects will be consuming the drug for the benefit of others, and participating communities will need education and explanations to understand this concept. Also, the communities need to be made aware that it would not be a prophylactic and therapeutic option for malaria. Ivermectin will be a supplementary measure and not a replacement of existing vector control methods. If proven successful via testing on Indian vectors, the deployment of ivermectin can be initially limited to certain hotspots that are experiencing persistent malaria outbreaks. India seems closer to malaria elimination than ever before, and yet we need newer vector management tools to cover regions with persistent malaria where conventional tools fall short in effective malaria control. 


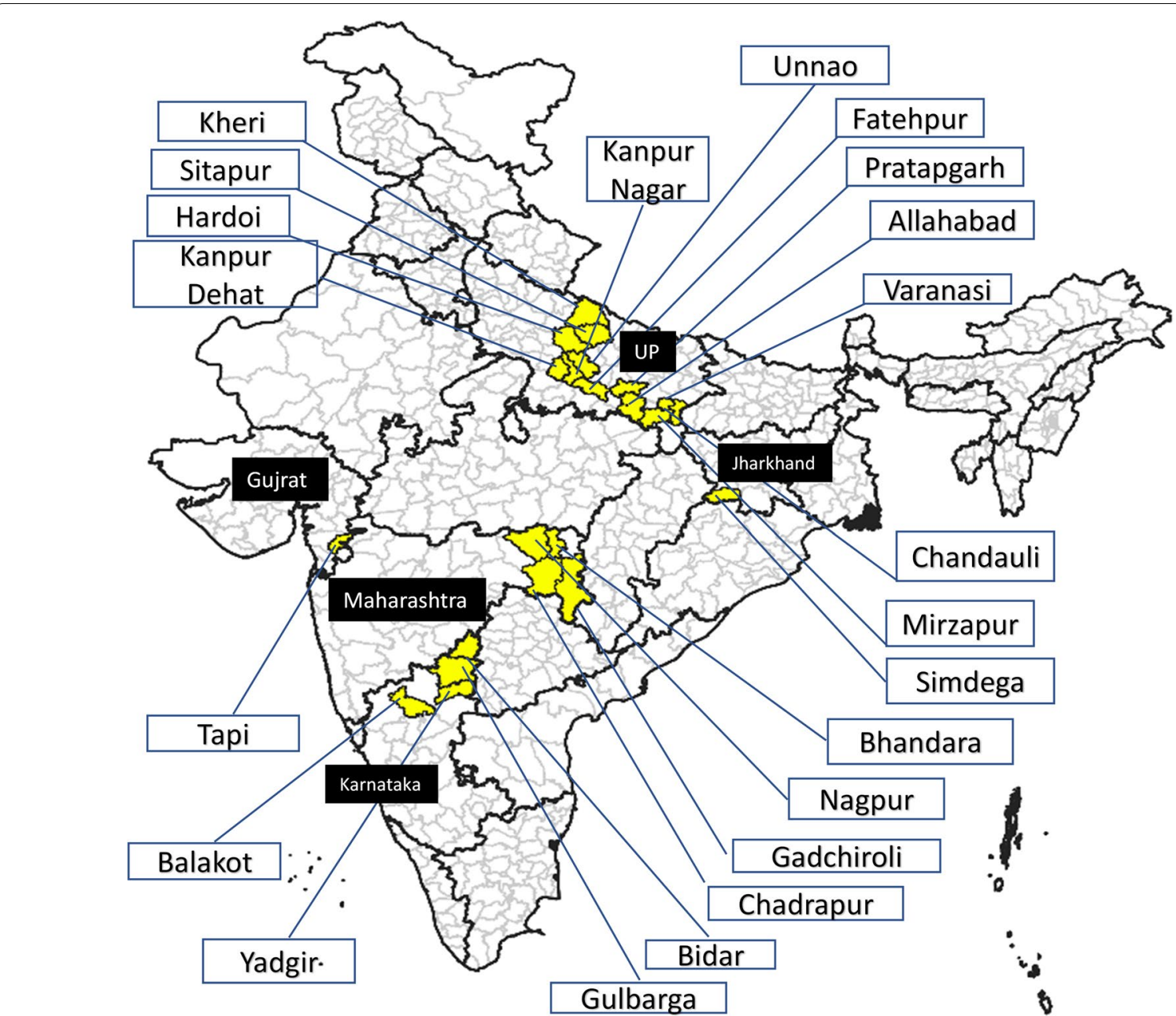

Fig. 2 Districts in India where which ivermectin is distributed in the National Programme to Eliminate Lymphatic Filariasis

\section{Conclusion}

Insecticide resistance and changing behaviour of the malaria vectors are crucial challenges to vector control strategies which can potentially weaken the drive towards malaria elimination in India. Among other novel methods/tools, the use of ivermectin as an endectocide holds promise, as shown in international animal and human trials. India is yet to explore the use of ivermectin as a mosquitocidal agent. This is an opportune time to assess ivermectin in Indian malaria vectors in a graded manner, beginning with testing the susceptibility of Indian vectors to ivermectin, followed by preclinical studies and then clinical studies in cattle and humans. The case scenario for the endectocide could be prioritized in consultation with the national programme and with sufficient sensitization and education of the communities. After these steps have been carried out, the possibility of deploying ivermectin as a vector control tool can be envisaged.
Acknowledgements

We thank Department of Science and Technology (DST) for the JC Bose fellowship to AS.

\section{Authors' contributions}

AS conceived the study. SSA carried out the extensive literature reviews. SSA and MR drafted the manuscript. MR made important additions. PS designed the figures. All authors wrote the paper. All authors read and approved the final manuscript.

Funding

Not applicable.

Availability of data and materials

This paper does not contain original data.

\section{Declarations}

Ethics approval and consent to participate Not applicable.

Consent for publication

Not applicable. 


\section{Competing interests}

None of the authors have any competing interests to declare.

\section{Author details}

${ }^{1}$ Indian Council of Medical Research (ICMR)-National Institute of Malaria Research, New Delhi, India. ${ }^{2}$ Indian Council of Medical Research, New Delhi, India. ${ }^{3}$ International Centre for Genetic Engineering and Biotechnology, New Delhi, India. ${ }^{4}$ Academy of Scientific and Innovative Research (AcSir), Ghaziabad, India.

Received: 13 August 2021 Accepted: 12 December 2021

Published online: 10 January 2022

\section{References}

1. Subbarao SK, Nanda N, Rahi M, Raghavendra K. Biology and bionomics of malaria vectors in India: existing information and what more needs to be known for strategizing elimination of malaria. Malar J. 2019;18:396.

2. World Health Organization (WHO) World malaria report 2020. 2019 https://www.who.int/publications/i/item/9789240015791 Accessed 30 May 2021.

3. Khaligh FG, Jafari A, Levchenko M, Rahimi B, Gholizadeh S. Endectocides as a complementary intervention in the malaria control program: a systematic review. Malar J. 2021;10:30.

4. Bhatt S, Weiss DJ, Cameron E, Bisanzio D, Mappin B, Dalrymple U, et al. The effect of malaria control on Plasmodium falciparum in Africa between 2000 and 2015. Nature. 2015;526:207-11.

5. Rath A, Prusty MR, Das M, Mahapatra N, Tripathy H, Hazra RK. A shift in resting habitat and feeding behavior of Anopheles fluviatilis sibling species in the Keonjhar district of Odisha, India. Trans R Soc Trop Med Hyg. 2015;109:730-7

6. Thomsen EK, Koimbu G, Pulford J, Jamea-Maiasa S, Ura Y, Keven $J B$, et al. Mosquito behavior change after distribution of bednets results in decreased protection against malaria exposure. J Infect Dis. 2017:215:790-7.

7. Sougoufara S, Ottih EC, Tripet F. The need for new vector control approaches targeting outdoor biting anopheline malaria vector communities. Parasit Vectors. 2020;13:295.

8. Lobo NF, Achee NL, Greico J, Collins FH. Modern vector control. Cold Spring Harb Perspect Med. 2018;8:a025643.

9. Laing R, Gillan V, Devaney E. Ivermectin_old drug, new tricks? Trends Parasitol. 2017;33:463-72.

10. Omura S, Crump A. Ivermectin and malaria control. Malar J. 2017:16:172.

11. The Ivermectin Roadmappers. A roadmap for the development of Ivermectin as a complementary malaria vector control tool. Am J Trop Med Hyg. 2020;102(Suppl 2):3-24.

12. World Health Organization (WHO)/Malaria Policy Advisory Committee Meeting (MPAC). Ivermectin for malaria transmission control. 2016 https://www.who.int/malaria/mpac/mpac-sept2016-invermectin-sessi on9.pdf?ua=1 Accessed 30 May 2021

13. MESA TRACK. http://www.mesamalaria.org/. Accessed 30 May 2021

14. Mekuriaw W, Balkew M, Messenger LA, Yewhalaw D, Woyessa A, Massebo F. The effect of ivermectin ${ }^{\circledR}$ on fertility, fecundity and mortality of Anopheles arabiensis fed on treated men in Ethiopia. Malar J. 2019:18:357.

15. Foy BD, Alout H, Seamen JA, Rao S, Magalhaes T, Wade M, et al. Efficacy and risk of harms of repeat ivermectin mass drug administrations for control of malaria (RIMDAMAL): a cluster-randomised trial. Lancet. 2019;393:1517-26.

16. Cramer EY, Quang NX, Hertz JC, Nguyen DV, Quang HH, Mendenhall I, et al. Ivermectin treatment for cattle reduced the survival of two malaria vectors, Anopheles dirus and Anopheles epiroticus, under laboratory conditions in Central Vietnam. Am J Trop Med Hyg. 2021;104(6):2165-8.

17. Naz SM, Ahmad A, Ahmad M, Zaman AS. Efficacy of ivermectin for control of zoophilic malaria vectors in Pakistan. Pak J Zool. 2013;45:1585-91.

18. Poche RM, Burruss D, Polyakova L, Poche DM, Garlapati RB. Treatment of livestock with systemic insecticides for control of Anopheles arabiensis in western Kenya. Malar J. 2015:14:351.

19. Chaccour CJ, Ngh'bi K, Abizanda G, Barrio Al, Aldaz A, Okumu F, et al. Targeting cattle for malaria elimination: marked reduction of Anopheles arabiensis survival for over six months using a slow-release ivermectin implant formulation. Parasit Vectors. 2018;11:287.

20. Imbahale SS, Lopez JM, Brew J, Paaijmans K, Rist C, Chaccour C. Mapping the potential use of endectocide-treated cattle to reduce malaria transmission. Sci Rep. 2019:9:5826.

21. National Center for Vector Borne Diseases Control (NCVBDC), Ministry of Health \& Family Welfare, Government of India. National Vector Borne Disease Control Programme. https://nvbdcp.gov.in/. Accessed 30 May 2021.

22. Sonavale KP, Shaikh MR, Kasam MM, Pokharkar VG. Livestock sector in India: a critical analysis. Asian J Agric Ext Econ Sociol. 2020;38(1):51-62.

23. Batiaens GJH, van Gemert GJ, Hoogof J, Lindsay SW,Drakeley C, Churcher TS, et al. Duration of mosquitocidal effect of ivermectin. Malar World J. 2012;3(10).

24. Ouedraogo AL, Bastiaens GJH, Tiono AB, Guelbeogo WM, Kobylinski KC, Ouedraogo A, et al. Efficacy and safety of the mosquitocidal drug ivermectin to prevent malaria transmission after treatment: a double-blind, randomized, clinical trial. Clin Infect Dis. 2016;60(3):357-65.

25. Smit MR, Ochomo EO, Waterhouse D, Kwambai TK, Abong'o BO, Bousema $T$, et al. Safety and mosquitocidal efficacy of high-dose ivermectin when co-administered with dihydroartemisinin-piperaquine in Kenyan adults with uncomplicated malaria (IVERMAL): a randomised, double-blind, placebo-controlled trial. Lancet Infect Dis. 2018;18(6):615-26.

26. Derua YA, Kisinza WN, Simonsen PE. Differential effect of human ivermectin treatment on blood feeding Anopheles gambiae and Culex quinquefasciatus. Parasit Vectors. 2015:8:130.

27. Sampaio VS, Beltran TP, Kobylinski KC, Melo GC, Lima JBP, Silva SGM, et al. Filling gaps on ivermectin knowledge: effects on the survival and reproduction of Anopheles aquasalis, a Latin American malaria vector. Malar J. 2016;15:491.

28. Kobylinski KC, Ubalee R, Ponlawat A, Nitatsukprasert C, Phasomkulsolsil S, Wattanakul T, et al. Ivermectin susceptibility and sporontocidal effect in Greater Mekong Subregion Anopheles. Malar J. 2017;16:280.

29. Fritz ML, Siegert PY, Walker ED, Bayoh MN, Vulule JR, Miller JR. Toxicity of bloodmeals from ivermectin-treated cattle to Anopheles gambiae s.l. Ann Trop Med Parasitol. 2009;103:539-47.

30. Pooda HS, Rayaisse JB, de Sale Hien DF, Lefevre T, Yerbanga SR, Bengaly $Z$, et al. Administration of ivermectin to peridomestic cattle: a promising approach to target the residual transmission of human malaria. Malar J. 2015;14:496.

31. Lyimo IN, Kessey ST, Mbina KF, Daraja AA, Mnyone LL. Ivermectin-treated cattle reduces blood digestion, egg production and survival of a freeliving population of Anopheles arabiensis under semi-field condition in south-eastern Tanzania. Malar J. 2017;16:239.

32. Makhanthisa TI, Braack L, Lutermann $H$. The effect of cattle-administered ivermectin and fipronil on the mortality and fecundity of Anopheles arabiensis Patton. Parasit Vectors. 2021:14:349.

\section{Publisher's Note}

Springer Nature remains neutral with regard to jurisdictional claims in published maps and institutional affiliations.

Ready to submit your research? Choose BMC and benefit from

- fast, convenient online submission

- thorough peer review by experienced researchers in your field

- rapid publication on acceptance

- support for research data, including large and complex data types

- gold Open Access which fosters wider collaboration and increased citations

- maximum visibility for your research: over 100M website views per year

At BMC, research is always in progress.

Learn more biomedcentral.com/submissions 